Int. J. Dev. Biol. 49: 259-267 (2005)

doi: $10.1387 / \mathrm{ijdb} .041941 \mathrm{ae}$

\title{
Vascular development: from precursor cells to branched arterial and venous networks
}

\author{
ANNE EICHMANN*, LI YUAN, DELPHINE MOYON, FERDINAND LENOBLE, \\ LUC PARDANAUD and CHRISTIANE BRÉANT \\ Inserm U36, Collège de France, Paris, France
}

\begin{abstract}
The adult vascular system is composed of an arterial, a venous and a lymphatic compartment. These different compartments respectively provide oxygen and nutrients to peripheral organs, remove carbon dioxide and waste products and maintain an immune barrier to defend the host against foreign organisms. Malfunctions of the vascular system represent a major cause of mortality and disease in developed countries. Understanding of the molecular mechanisms regulating vascular system development and maintenance is thus crucial for the design of therapies to cure vascular diseases. The molecules implicated in the control of physiological and pathological angiogenesis in the adult already function during embryonic development. Indeed, the survival of the embryo also critically depends on the establishment of a functional circulatory loop. Here we review our current knowledge about the emergence of endothelial precursor cells in the embryo, of their assembly into the primary vascular plexus and of the remodeling of this plexus into arteries and veins. We also focus on the molecular mechanisms controlling the development of arteries, veins and lymphatic vessels.
\end{abstract}

KEY WORDS: endothelial cell, vasculogenesis, angiogenesis, arterio-venous differentiation, growth factor receptor, plasticity, flow

\section{Introduction}

All vertebrates require a mechanism to distribute oxygen and nutrients to tissues and to remove carbon dioxide and other metabolic waste products, which have to be transmitted to the excretory organs. The circulatory system carries out these vital functions via its two main components, the blood-vascular and the lymphatic system (Fig. 1). Blood, which is the carrier of oxygen, carbon dioxide and metabolic products, is pumped from the heart through the arterial system into the tissue capillary bed, where exchanges occur. The blood is then channeled through the venous system back into the heart. The blood-vascular system is affected by numerous pathologies, including artherosclerosis and cancer, the two major causes of death in developed countries (Carmeliet and Jain, 2000; Cines etal., 1998; Ferrara and Alitalo, 1999; Folkman, 1995, for reviews). The lymphatic system drains extravasated fluid, the lymph, from the extracellular space and returns it into the venous circulation. The lymphatic vasculature is also essential for the immune defense, as lymph and any foreign material present in it, such as microbial antigens, are filtered through the chain of lymph nodes (Fig. 1). Defects in lymphatic development or damage to the lymphatics provoke lymphedema, a disabling and disfiguring swelling of the extremities. In addition, many cancer cell types use the lymphatic vessels for their metastatic spread (Alitalo and Carmeliet, 2002, for review).

Histologically, the structure of blood vessels is rather simple. The capillary bed, which comprises the largest surface of the vascular system, is composed solely of endothelial cells (EC), occasionally associated with external pericytes. These simple capillary tubes are surrounded by a basement membrane. Larger vessels have additional layers constituting the vessel wall, which are composed of a muscular layer, the tunica media and an outer connective tissue layer called tunica adventitia containing vasa vasorum and nerves (Wheater etal., 1978). The size of the vessel wall varies according to the vessel size and type. The main focus of this review will be on EC, which represent the major cellular compartment of the vascular system and which are the first to form during embryonic development.

Abbreviations used in this paper: EC, endothelial cell; PDGF, platelet-derived growth factor; VEGF, vascular endothelial growth factor.

\footnotetext{
*Address correspondence to: Dr. Anne Eichmann. Inserm U36, Collège de France, 11, Place Marcelin Berthelot, 75005 Paris, France. Fax: +33-1-44271691. e-mail: anne.eichmann@college-de-france.fr
} 


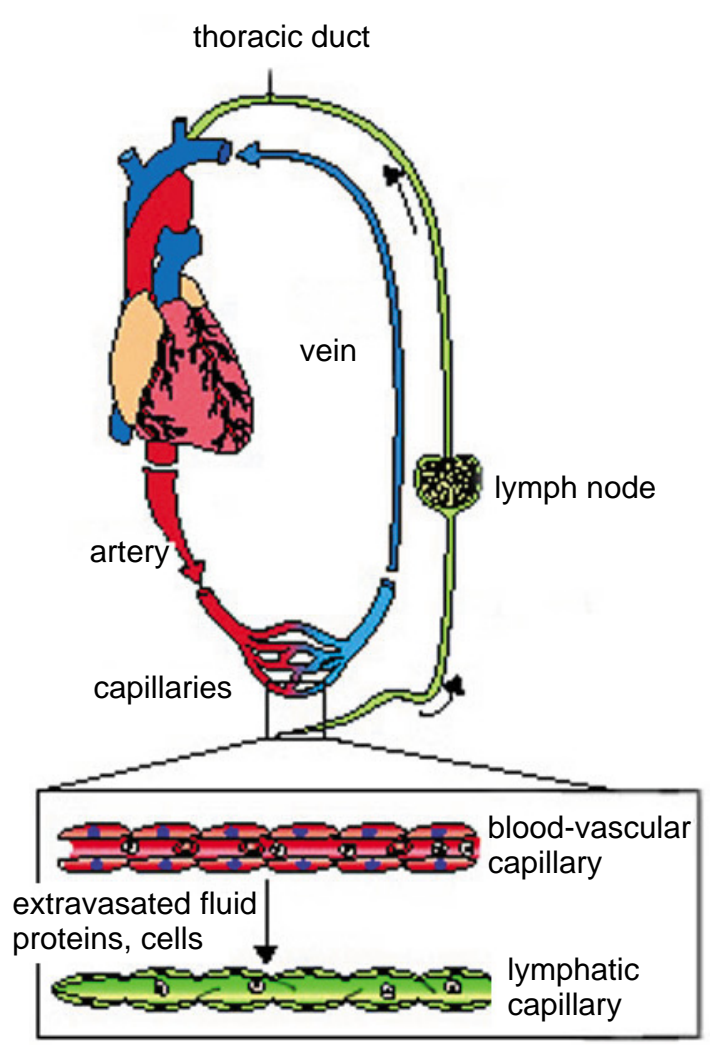

Fig. 1. Schematic representation of the circulatory system. (Modified from Karkkainen et al., 2002). Blood is pumped from the heart through arteries, arterioles and capillaries to the tissues, where exchanges occur. Blood is returned to the heart via the venous circulation. The lymphatic system, composed of lymphatic capillaries and vessels, drains excess fluid, the lymph, containing proteins, lipids and immune cells, from the extracellular space and returns it to the venous circulation.

\section{Emergence of EC during embryonic development}

As the diffusion distance of molecules is limited (100-200 $\mu \mathrm{m}$ for $\mathrm{O}_{2}$ for example), the vascular system in any organ and tissue has to be established early during development. The cardiovascular system is actually the first organ system formed during early embryonic development. EC differentiation is first observed during gastrulation, when cells invaginate through the primitive streak to form the mesoderm. Newly formed mesodermal cells soon organize into axial mesoderm (notochord), paraxial mesoderm (somites) and intermediate mesoderm (kidney and gonads) (Fig. 2A). The lateral plate mesoderm is situated on both sides of the intermediate mesoderm and will split into two layers after the formation of the coelome: a dorsal sheet, the somatopleural mesoderm and a ventral sheet, the splanchnopleural mesoderm. The dorsal sheet is in contact with the ectoderm and will form the body wall and limbs while the ventral sheet is in contact with the endoderm and will form the visceral organs. The posterior part of the mesoderm, which occupies about half of the embryo during early gastrulation stages, will give rise to the extraembryonic mesoderm. The first endothelial cells that form in the gastrulating embryo originate from lateral and posterior mesoderm, as shown by Murray (Murray, 1932). Murray dissected 24-hour old chick embryos into small pieces, which were cultured in vitro to obtain blood cells, visible by their hemoglobin content. The posterior two thirds of the embryo, corresponding to the presumptive territories of lateral and posterior mesoderm (Fig. 2A) were found to give rise to blood cells, as well as to EC. More recently, we have shown that these territories expressed the vascular endothelial growth factor receptor -2 (VEGFR2) (Fig. 2B) (Eichmann et al., 1993).

Vascular endothelial growth factor (VEGF) and its receptor VEGFR2 are the most critical drivers of embryonic vessel formation (Yancopoulos et al., 2000 for review). VEGF is expressed in spatial and temporal association with almost all physiological events of vascular formation in vivo (Jakeman et al., 1993; Shweiki et al., 1993). VEGFR2 expression is already observed at very early stages of development (Fig. 2B) and subsequently becomes mainly restricted to EC of all types of blood vessels as well as lymphatic vessels (Eichmann etal., 1993; Wilting etal., 1997; Yamaguchi etal., 1993). Mice deficient in VEGFR2 (VEGFR2--1) died in utero between 8.5 and 9.5 days post-coitum, as a result of an early defect in the development of $\mathrm{HC}$ and EC. Yolk-sac blood islands were absent at 7.5 days, organized blood vessels could not be observed in the embryo or yolk sac at any stage and hematopoietic progenitors were absent (Shalaby etal., 1995). VEGF deficient mouse embryos also die at E8.5 to E9.5 and exhibit severe phenotypes similar to that of the VEGFR2-- mice; this phenotype was also observed in the $\mathrm{VEGF}^{+/}$embryos (Carmeliet etal., 1996; Ferrara etal., 1996). The lethality resulting from the loss of a single allele is indicative of a tight dose-dependent regulation of embryonic vessel development by VEGF. Taken together, the results described above confirm the major position of the VEGF/ VEGFR2 system in vascular formation.

The newly formed lateral and posterior mesodermal cells migrate toward the yolk sac, where they will differentiate to $\mathrm{EC}$ and to $\mathrm{HC}$ of the blood islands. During their migration, the precursors aggregate to clusters, termed hemangioblastic aggregates. These were first described by F. Sabin (Sabin, 1920), who studied their migration under the light-microscope. She could distinguish the hemangioblastic aggregates from the remaining mesodermal cells by their increased refringence. The peripheral cells of these aggregates subsequently
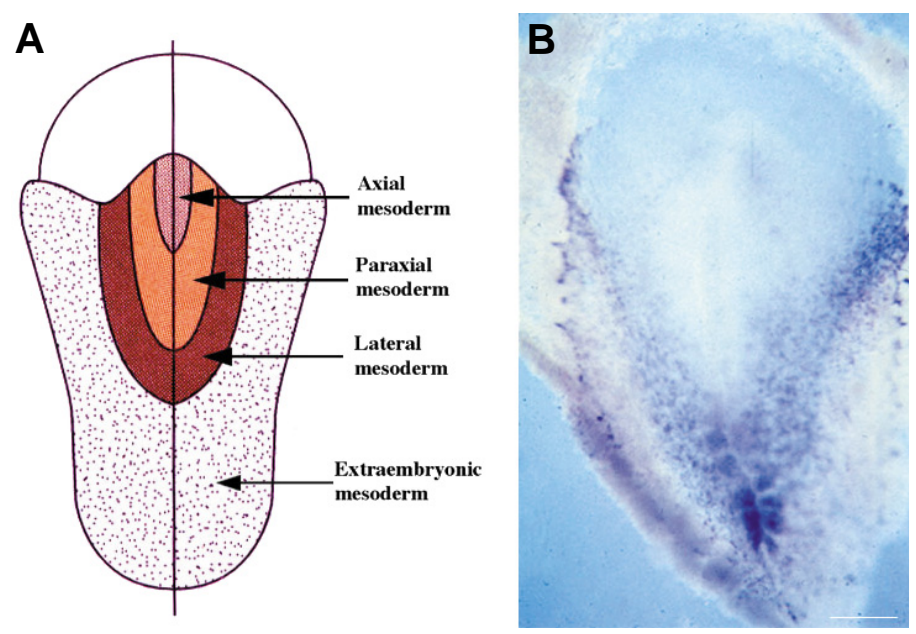

Fig. 2. Origin of endothelial cells in the gastrulating chick embryo. (A) Map of presumptive embryonic territories (from Vakaet, 1985). (B) Labeling of a chick embryo at stage 4 of Hamburger and Hamilton (Hamburger and Hamilton, 1951), corresponding to the stage shown in A, with an antisense riboprobe specific for VEGFR2. The presumptive extraembryonic and lateral mesoderm expresses this receptor. 
flatten and differentiate to EC, while the centrally located cells differentiate to $\mathrm{HC}$ (Fig. 3A). The simultaneous emergence of EC and $\mathrm{HC}$ in the blood islands led to the hypothesis that they were derived from a common precursor, the hemangioblast(Sabin, 1920). VEGFR2 expression during successive stages of hemangioblast differentiation shows that gastrulating precursors as well as hemangioblastic aggregates are positive, while in the differentiated islands only the EC express this gene and no expression is detected in $\mathrm{HC}$ (Fig. 3B). These observations are compatible with the hypothesis that VEGFR2 labels a bipotent progenitor and that after lineage diversification; only one of the two daughter cells maintains expression of this gene.

To test this idea, we prepared a monoclonal antibody directed against the extracellular domain of quail VEGFR2 (Eichmann et al., 1997). Using this antibody, we isolated cells from posterior territories of embryos at the gastrulation stage (Fig. 2A), which were subsequently cultured in semi-solid medium in vitro. In the absence of added VEGF, the VEGFR2+, but not the VEGFR2-precursors differentiated to $\mathrm{HC}$ of different lineages. In the presence of VEGF, EC differentiation of the VEGFR2+ precursors was induced. These experiments showed that VEGFR2+ precursors could indeed give rise to EC as well as $\mathrm{HC}$, consistent with the hypothesis that this receptor is expressed by a common precursor. However, at the single cell level, an individual VEGFR2 + cell would either differentiate to an EC or an HC, but not both, precluding a direct demonstration of the existence of a 'hemangioblast'. In cultures derived from mouse ES cells, a single VEGFR2+ cell was found to be able to give rise to both EC as well as HC (Choi et al., 1998; Nishikawa et al., 1998). This cell is currently referred to as the 'hemangioblast' in the literature. However, additional studies have shown that ES cell-derived VEGFR2+ cells can also give rise to smooth muscle cells in the presence of platelet-derived growth factor (PDGF)(Yamashita et al., 2000), indicating that rather than being strictly committed to only the $\mathrm{EC}$ and the $\mathrm{HC}$ lineage, these cells may be pluri-or multipotent progenitors.

\section{Formation of the primary capillary plexus}

Following the differentiation of the yolk sac blood islands, EC surrounding these blood islands soon anastomose to form a capillary meshwork, which serves as a scaffold for the beginnings of circulation (Fig. 3, 4A). The embryo has thus laid down the rudiments of its extraembryonic vascular system before the onset of heart beat around the 12-somite stage in the chick. Inside the embryo proper, one major vessel, the dorsal aorta, as well as numerous capillaries have differentiated (Fig. 4A). EC differentiation in the embryo proper during this developmental time window occurs in the absence of associated hematopoiesis. After the onset of heartbeat and of blood flow, the yolk sac capillary plexus is rapidly remodeled into arteries and veins and a functional circulatory loop essential for survival is established (Fig. 4B). The newly formed blood island $\mathrm{HC}$ are channeled through this primitive circulation. These yolk sac hematopoietic precursors mostly differentiate into primitive erythrocytes, which are replaced, as development proceeds, by definitive hematopoietic precursors generated in the embryo proper (Cumano et al., 2001; Dieterlen-Lievre, 1975). These definitive precursors are again observed to develop in close association with the endothelium of the dorsal aorta (Jaffredo etal., 1998; Pardanaud et al., 1996).

Collectively, the in situ differentiation of EC from the mesoderm and their coalescence into tubes of the primary capillary plexus are called vasculogenesis (Risau, 1997). Vasculogenesis results in the formation of the major embryonic vessels, the dorsal aorta and of the primary vascular plexus in the yolk sac. In the chick embryo, both are formed before the 14ss, prior to the onset of perfusion. Fig. $4 \mathrm{~A}$ shows the structure of the primary capillary plexus at this stage revealed by immunohistochemistry with the $\mathrm{QH} 1$ antibody, specific for EC in the quail (Pardanaud et al., 1987).

\section{Remodeling of the capillary plexus into arteries and veins}

Over the next few hours, the primary vascular plexus has to be remodeled into a system with arteries and veins, to accommodate the output of the heart and to establish the primary circulation. This step is critical for the embryo's survival and indeed, many mouse mutants for genes involved in vascular development die during this 'remodeling' phase (Roman and Weinstein, 2000, for review). We have recently performed a detailed analysis of the remodeling of the primary vascular plexus into arteries and veins in the chick embryo yolk sac, using time-lapse video-microscopy (LeNoble et al., 2004). Fig. 4B shows a chick embryo about 24 hours older than the embryo in Fig. 4A, it is obvious that the primary capillary plexus has been remodeled into larger and smaller vessels. The chick
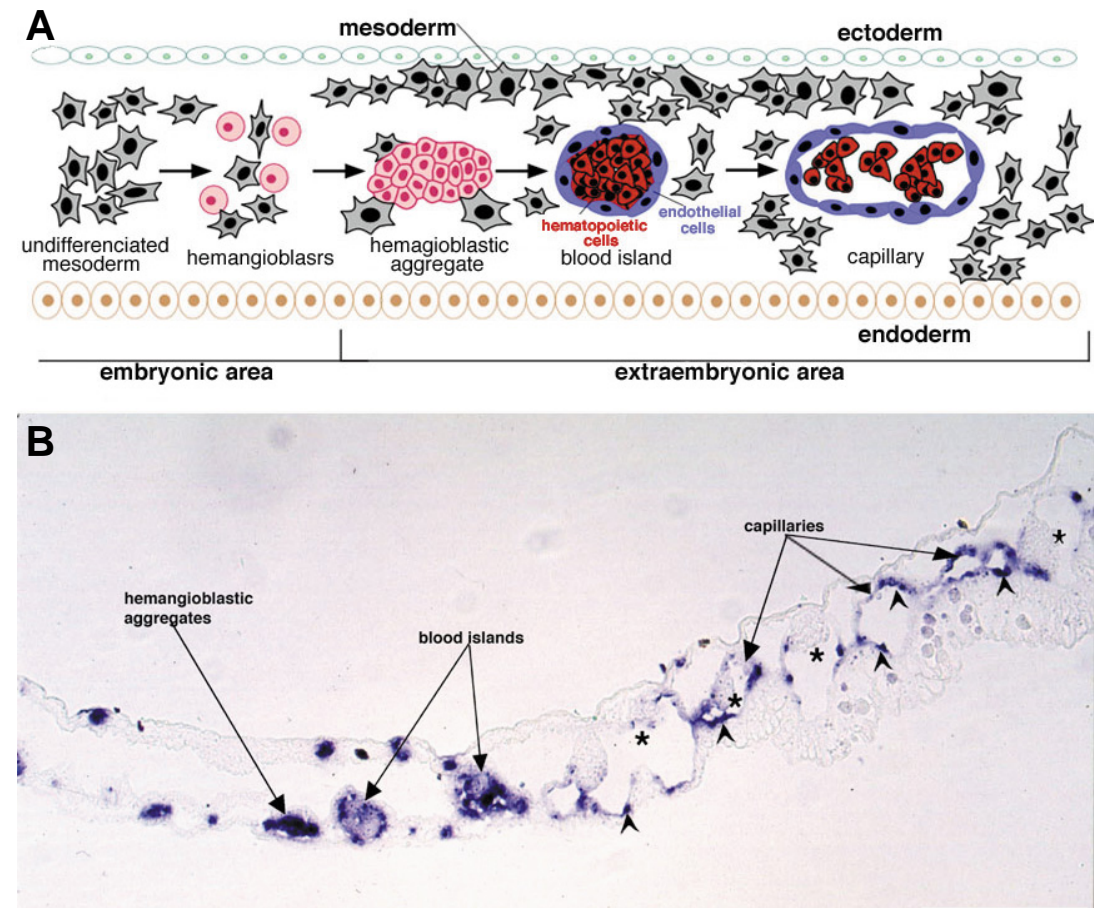

Fig. 3. Differentiation of yolk sac blood islands. (A) Schematic representation: see text for details. (B) Transverse section through the extraembryonic area of a 15-somite stage embryo, labeled with an antisense riboprobe specific for VEGFR2. Hemangioblastic aggregates are positive. In the blood islands and capillaries, expression of the receptor decreases in the hematopoietic cells (asterisks), but is maintained in the endothelial cells (arrowheads). Bar, $75 \mu \mathrm{m}$. 
Fig. 4. Arterial-venous differentiation in the yolk sac. (A) Primary capillary plexus stage. Labeling of a 10-somite stage quail embryo with the $\mathrm{QH} 1$ antibody. Note labeling of the endocardium (asterisk) and the paired dorsal aorta (DA, arrows). At this stage, only these two major vessels are formed, the remainder of the vascular system is seen as a capillary plexus. (B) Photo-micrograph of a living chick embryo 24 hours older than the embryo in A. The heart is indicated (asterisk). Note that in the yolk sac, two main arteries, the vitelline arteries (VA) have formed. Arterial blood (red arrows) is pumped from the heart through the dorsal aorta (DA) and the vitelline arteries into the yolk sac and is returned to the heart via the venous circulation (blue arrows) either directly or through the sinus vein (SV). (C) Onset of formation of the posterior vitelline vein. Embryo at the same stage as in $B$. Intracardiac injection of Dil-Ac-LDL, which specifically recognizes endothelial cells. Note the dorsal aorta and vitelline artery. As more flow passes through these vessels, they enlarge. Smaller vessels of the initial arterial capillary plexus (black arrow) carry progressively less flow and are disconnected from the main branch of the dorsal aorta. As

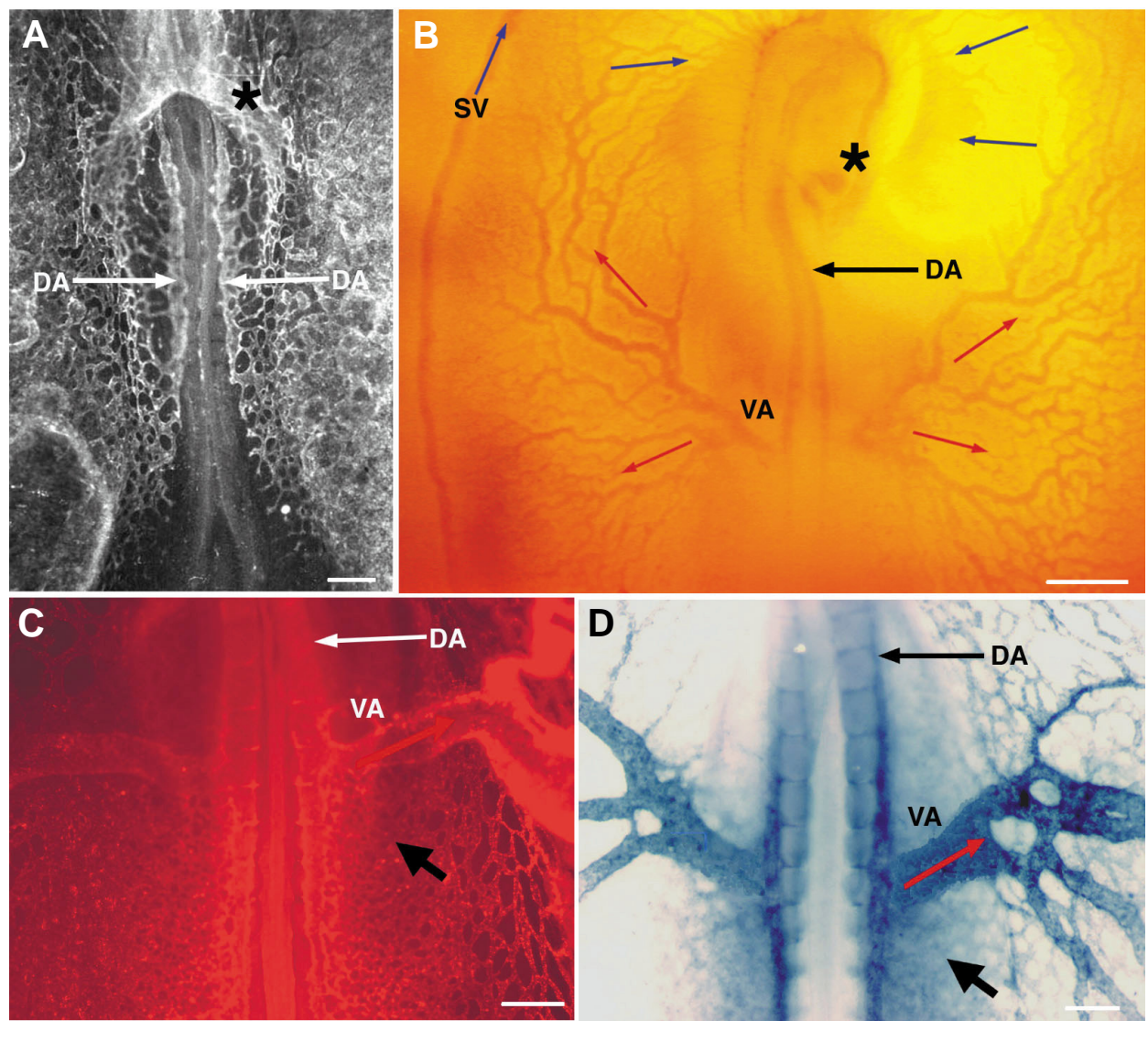

shown by the intracardiac injection, these vessels are still perfused through more distal parts of the capillary plexus. They will be used to form the posterior vitelline vein. (D) Arterial marker expression. In situ hybridization with an antisense riboprobe specific for NRP-1. Note strong expression in the vitelline artery (VA), but reduced expression in the disconnected capillaries that will form the vitelline vein (black arrow). Bars $250 \mu \mathrm{m}$.

offers the possibility of direct visual inspection of the blood flow and the direction of circulation can thus be easily visualized in living embryos. As indicated in Fig. 4B, arterial blood pumped from the heart through the dorsal aorta enters the yolk sac through the vitelline artery and its branches. To be returned towards the heart, blood either reaches the peripheral sinus vein and is returned through the anterior venous plexus (Fig. 4B), or blood can flow directly back towards the heart. Indeed, close visual inspection of the circulatory system at this stage reveals that arterial and venous blood actually flows through the same vascular channel. The definition of arterial and venous blood is given in this case simply by the direction of the blood flow away from (arterial) or towards (venous) the heart. This embryonic vessel configuration is in contrast to the adult situation where blood flows through arteries into successively smaller arterioles, a capillary bed and through successively larger venules and veins back to the heart. In fact, if the embryonic arterial-venous vessel configuration would persist, large arterial-venous shunts would develop and distal parts of the yolk sac would not be perfused, resulting in death of the embryo. The embryo has solved this 'plumbing' problem in a simple manner: during the formation of the large vitelline artery from the primary capillary plexus, not all capillaries are integrated into this tube: some small side branches become disconnected (Fig. 4C, D). The disconnection of side branches is regulated by perfusion: the increased flow in the main branch leads to a diameter decrease and subsequent obstruction of the lumen of the side branch (LeNoble, F., Eichmann, A., Nguyen, T.H., Fleury, V., submitted). These disconnected vessels are subsequently used to fashion the embryonic veins of the secondary circulation, which come to lie dorsally and parallel to the arteries (LeNoble et al., 2004). To become reconnected to the venous circulation, the disconnected side branches sprout dorsally and perpendicular to the arteries. The molecular basis underlying the directed sprouting is currently unknown but may involve some of the neuronal guidance receptors expressed in developing arterial and venous EC (see below).

\section{Molecular markers specific for arteries and veins}

Based on classic studies, it was believed that EC of the primary capillary plexus constitute a rather homogenous group of cells and that differentiation into arteries and veins occurred due to the influence of hemodynamic forces (Thoma, 1893). Over the last few years, however, several signaling molecules were discovered, which labeled arterial or venous EC from early developmental stages onward, prior to the assembly of a vascular wall. Interestingly, most of these molecules are also expressed in the nervous system, where they regulate cell fate decisions and guidance of migration of neuronal precursors as well as of developing axons (Artavanis-Tsakonas et al., 1999; Flanagan and Vanderhaeghen, 1998; Kullander and Klein, 2002; Neufeld et 
al., 2002; Raper, 2000). It is thus tempting to speculate that these molecules regulate similar cell behaviors in the developing nervous and vascular system. Arterial EC in chick, mouse and zebrafish selectively express ephrin-B2, neuropilin-1 (NRP-1) and members of the Notch pathway, including notch3, DLL4 and gridlock (Herzog et al., 2001; Lawson et al., 2001; Moyon et al., 2001a; Moyon et al., 2001b; Shutter et al., 2000; Villa et al., 2001; Wang et al., 1998; Zhong et al., 2000). Other molecules are specifically expressed in the venous system, most notably EphB4, the receptor for arterial ephrin-B2 (Gerety et al., 1999). The neuropilin-2 (NRP-2) receptor is expressed by veins and, at later developmental stages, becomes restricted to lymphatic vessels in chick and mice (Herzog et al., 2001; Yuan et al., 2002). Based on these specific expression patterns and on mutant studies in zebrafish and mouse, it has been suggested that embryonic arterial-venous differentiation is actually genetically predetermined (Wang et al., 1998). In support for this idea, tracing of individual fluorescently labeled angioblasts in the zebrafish embryo showed that a single EC precursor will give rise to an arterial or a venous, but not to mixed clones (Zhong et al., 2001).

A possible role for these signaling molecules in arterial-venous differentiation was suggested by the phenotypes of ephrinB2 and EphB4 knockout mice: embryos displayed symmetrical phenotypes, remodeling of the primary vascular plexus into arteries and veins was arrested during early development, leading to death around E9.5 (Adams etal., 1999; Gerety etal., 1999; Wang etal., 1998). Inactivation or other signaling molecules specifically expressed by arteries, such as NRP-1 and members of the Notch family also leads to embryonic lethality due to failure of vascular system remodeling (Kawasaki et al., 1999; Swiatek et al., 1994; Xue et al., 1999). In these latter mutants, a specific effect on arteries has not been described, rather a general failure to form large and small vessels in the yolk sac has been noted. Zebrafish mutant studies have shown the requirement for Notch signaling to repress venous fate in arteries: inhibition of the Notch signaling pathway using a dominant negative form of suppressor of hairless $(\mathrm{SuH})$, a downstream effector of Notch, leads to ectopic expression of venous markers in arteries and to vascular malformations (Lawson et al., 2001). These observations led to the hypothesis that the embryonic vascular system could actually be predetermined to an arterial or venous fate from early developmental stages onward.

\section{Arterial-venous differentiation involves EC plasticity}

Our own work has shown that a considerable degree of EC plasticity is observed during arterialvenous differentiation. In a first series of experiments, we have isolated arterial or venous vessel fragments from quail embryos at different developmental stages, together with their vessel wall. These fragments were grafted into the coelome or in place of a somite in an E2 chick host (Moyon et al., 2001a). Progeny of the grafted EC could be traced in the host embryo using the QH1 antibody, specific for quail EC but not recognizing host $\mathrm{EC}$ (Pardanaud et al., 1987). To determine if the grafted EC colonized arteries or veins of the host, we used in situ hybridization with ephrinB2 or NRP-1 probes, which recognize arterial, but not venous EC of both species. We could then ask if EC from a grafted quail artery would only colonize chick arteries or also veins. These experiments showed that until late developmental stages (E11), quail EC from arteries or veins colonized both host arteries and veins with equal efficiency. Moreover, the expression of arterial markers changed according to the novel environment: when the quail cells colonized an artery, they expressed arterial markers, when they colonized a vein, they did not, irrespective of their origin. Thus, EC are plastic with respect to arterial-venous differentiation until E11. After E11, EC derived from a grafted artery would only colonize host arteries, while those from a vein would only colonize host veins. Quantification of the number of grafted EC showed that this loss of plasticity affected the vast majority (98\%) of all grafted EC. These experiments suggested some intrinsic changes in the grafted arteries and veins after E11 that restricted their capacity to colonize respectively host veins and arteries. To determine the source of the plasticity-restricting signal, we removed the vessel wall from E14 quail aortic fragments, this fully restored their

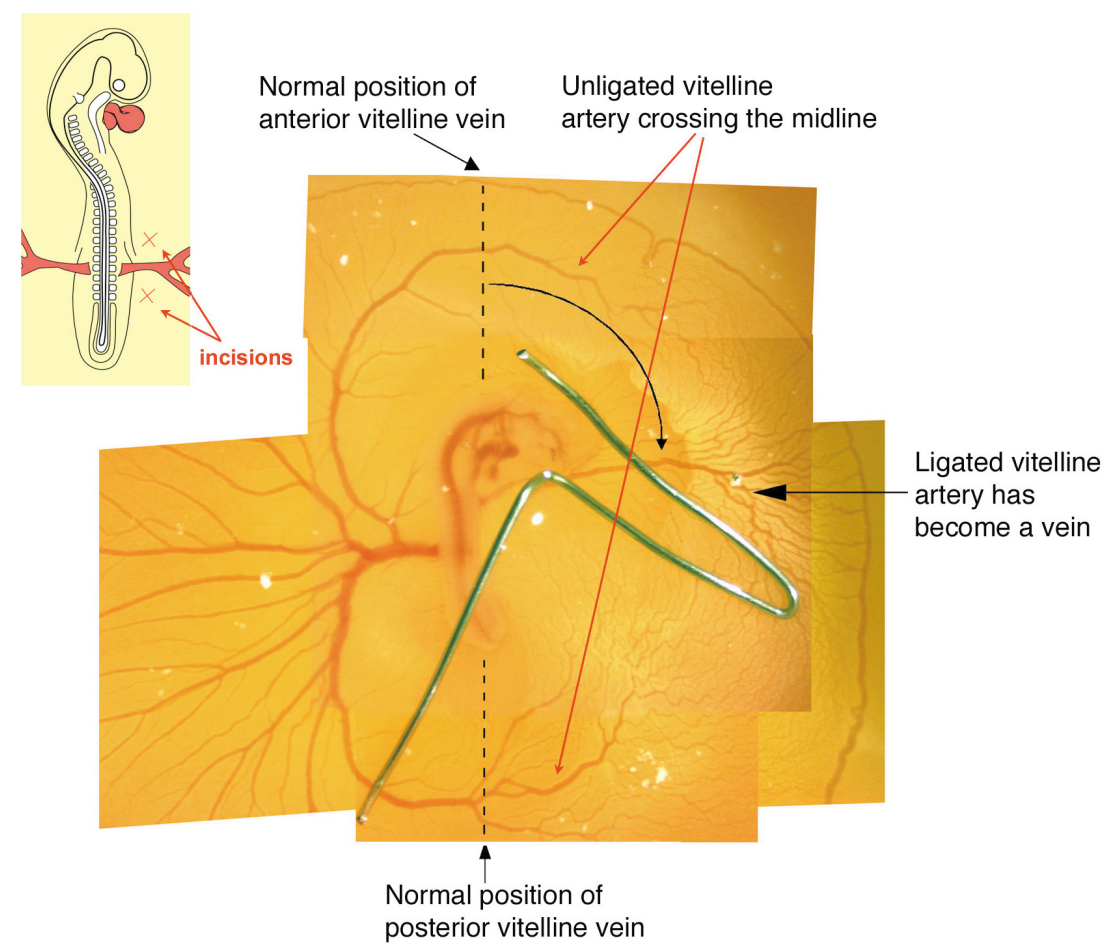

Fig. 5. Flow manipulations transform arteries into veins and veins into arteries. Ligation of the right vitelline artery of a chick embryo (Stephan, 1952). The schematic drawing shows the experimental manipulation: two small incisions are made on each side of the vitelline artery, a metal clip is then inserted underneath this artery. The clip is devised such that it lifts the right vitelline artery and blocks blood flowing through it. The photomicrograph shows such an embryo 24 hours after ligation: note that the right vitelline artery has been transformed into a vein. The normally present anterior and posterior vitelline veins are absent: they have been incorporated into the unligated left vitelline artery, which crosses the midline of the embryo/yolk sac axis. 
capacity to colonize veins: about $50 \%$ of grafted cells were found in arteries and $50 \%$ in veins. The precise nature of the plasticityrestricting signal coming from the vessel wall is yet unknown.

\section{Yolk sac arterial-venous differentiation is flow-regulated}

To determine if EC plasticity with respect to arterial-venous differentiation also occurred during normal embryonic development, we examined yolk sacs of embryos at different stages using a combination of time-lapse video-microscopy on living embryos and in situ hybridization with arterial and veinspecific markers (LeNoble et al., 2004). We observed that prior to the onset of circulation, arterial markers are expressed in the arterial capillary plexus of the posterior pole of the embryo, the territory where the vitelline artery will form. As described above, many small capillary branches of this arterial plexus become disconnected from the main branch of the vitelline artery during its formation. Arterial marker expression in these disconnected branches is rapidly down-regulated (Fig. 4D). In contrast, arterial marker expression is maintained in the newly formed vitelline artery (Fig. 4D). The disconnected capillaries that have downregulated arterial markers now serve to form the vitelline vein. These observations show that the posterior vitelline vein is formed by incorporating previously arterial capillary segments, demonstrating that $\mathrm{EC}$ plasticity is required during normal arterialvenous differentiation. Moreover, these experiments suggested that hemodynamic forces play a major role during arterial-venous differentiation and patterning.

To test this idea directly, we performed several alterations in the flow pattern of developing chick embryos (LeNoble et al., 2004). We first generated embryos devoid of a circulatory system by destroying the embryonic heart. In these embryos, the yolk sac continues to grow for at least 7 days, in spite of the degeneration of the embryo and the lack of perfusion. However, the yolk sac does not develop arteries or veins and remains in the configuration of a primary vascular plexus. In situ hybridization with arterial markers showed that some regions of this yolk sac expressed the arterial marker ephrinB2, while others did not. Thus, initiation of arterial marker expression occurs independently of flow.

We next performed ligations of the vitelline artery on one side of the yolk sac (Fig. 5) (Stephan, 1952). In these embryos, the entire ligated side becomes venularized over a period of 24 hours, as judged first by the direction of blood flow, which becomes reversed in the ligated vessels and second by the expression of arterial markers, which decreases rapidly following ligation (LeNoble et al., 2004). Thus, manipulation of the flow pattern can morphologically and genetically transform arteries into veins. The same flow manipulation can also transform veins into arteries. Indeed, the vitelline artery on the unligated side significantly enlarges after ligation, since it receives more flow. Subsequently, this artery crosses over the midline of the embryo-yolk sac axis both on the anterior and on the posterior pole of the embryo (Fig. 5). Time-lapse video-microscopy shows that branches of the anterior vitelline vein are integrated into the vitelline artery as it crosses the midline. Flow therefore appears as the masterregulator of arterial-venous differentiation in the yolk sac. Rather than being pre-determined, the yolk sac vessel EC appear as 'bricks' that can be used and re-used by the developing vascular system to fashion arteries or veins.

\section{Formation of the lymphatic vascular system}

Lymphatics are the last vascular compartment to be formed during development. Florence Sabin proposed the first theory on lymphatic vessel formation. Based on observation of ink-injected chick embryos, she concluded that the earliest primitive lymphatics arise as a result of EC sprouting from the cardinal veins. Subsequently, these cells proliferate and migrate toward the organs of the embryo and form the lymphatic system (Sabin, 1902). Other studies suggested that the connection of the lymphatic and venous systems was secondary. They proposed that lymphatic stem cells, called lymphangioblasts, invaded the mesenchyme in order to form primitive lymphatic sacs (Huntington and McClure, 1908; Kampmeier, 1912). Recent work using chick embryo limb buds has shown that lymphatic vessels can be derived both by sprouting of vessels from the cardinal vein and by mesodermal lymphangioblasts (Schneider et al., 1999; Wilting et al., 2001; Wilting et al., 2000).

Specific markers for lymphatic EC have recently been identified, providing new tools for the study of lymphangiogenesis. In addition, gene inactivation experiments have identified different molecules implicated in successive steps of the development of the lymphatic system (Fig. 6).

The earliest marker for developing lymphatic EC is the homeobox transcription factor Prox-1 (prospero-related homeobox protein-1) (Wigle and Oliver, 1999). Prox-1 first becomes expressed in the vascular system in the lateral aspect of the posterior cardinal vein at E9, shortly before the onset of sprouting of

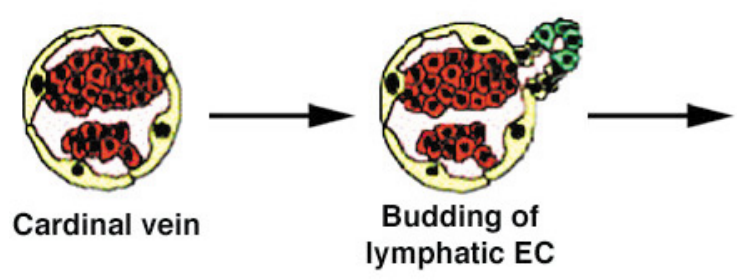

Prox-1-/-

No lymphatic EC specification

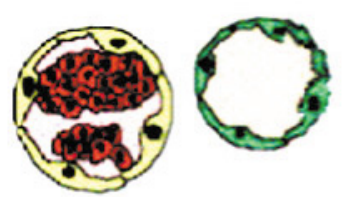

Formation of lymph sacs

VEGF-C-/No migration of lymphatic EC

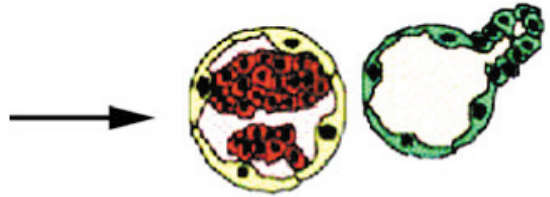

Sprouting of lymphatic vessels to periphery

NRP-2-/-

Reduced sprouting of lymph vessels

Fig. 6. Formation of the lymphatic vascular system. Schematic drawing representing the initial steps of lymphatic vessel formation. Mouse mutants implicated in these steps are indicated. See text for details. 
lymphatic EC from this vein. Inactivation of Prox-1 results in the complete absence of formation of lymphatic EC. Detailed examination of the phenotype of Prox-1-/- mice has shown that budding of lymphatic EC from the lateral aspect of the cardinal vein occurs. However, the budding cells fail to acquire expression of lymphatic-specific markers and instead continue to express blood-vascular markers, which normally are down-regulated after budding (Wigle et al., 2002). Lymphatic EC specification thus depends on the presence of Prox-1.

After specification of lymphatic EC has occurred, these cells normally migrate to form the first embryonic lymph sacs. Migration of the lymphatic EC towards the lymph sacs critically depends on the presence of the growth factor VEGF-C: in mice deficient for this growth factor, Prox-1 expressing lymphatic EC are formed, but fail to migrate towards the lymph sacs and subsequently die (Karkkainen et al., 2004). VEGF-C-/- embryos die at around E17 of development due to formation of massive oedema, since they do not develop any lymphatic vessels. VEGF-C specifically binds to its high affinity tyrosine kinase receptor VEGFR3 (Alitalo and Carmeliet, 2002 for review). During embryogenesis, VEGFR3 is first expressed in a subset of blood vascular EC and subsequently becomes restricted to lymphatic EC (Kaipainen et al., 1995; Wilting et al., 1997). Consistent with the early expression, VEGFR3 involvement in embryonic angiogenesis has been confirmed by targeted gene inactivation (Dumont et al., 1998). The VEGFR3 deficient mice showed defective blood vessel development at early embryonic stages and the embryos died at E9.5. Vasculogenesis and angiogenesis occurred, but large vessels became abnormally organized with defective lumens, leading to fluid accumulation in the pericardial cavity and cardiovascular failure (Dumont et al., 1998). Thus VEGFR3 has an essential function in the remodeling of the primary capillary vasculature prior to formation of the lymphatic vessels.

VEGF-C also binds to the NRP-2 receptor, which is specifically expressed by veins and subsequently becomes restricted to lymphatic vessels (Karkkainen et al., 2001; Yuan et al., 2002). In accordance with this specific expression, we have shown that mice deficient for NRP-2 show selective defects in the formation of lymphatic vessels (Yuan et al., 2002). Interestingly, however, the phenotypes of VEGF-C and NRP-2 deficient mice appear distinct. In NRP-2-/-mice, formation of lymph sacs occurs normally, while sprouting of lymphatic vessels from the lymph sacs to the periphery is reduced (Fig. 6). The precise molecular mechanisms regulating the different steps of embryonic lymphangiogenesis thus remain to be fully elucidated.

\section{Perspectives}

Research carried out over the past decade has provided major insights into the mechanisms regulating the emergence of endothelial progenitors from the mesoderm, their coalescence into the primary vascular system, the remodeling of this system into arteries and veins as well as into the formation of lymphatic endothelium. The molecules implicated in these different developmental processes are also essential for the maintenance of the adult vascular system. For example, patients suffering from hereditary lymphedema have been found to carry a mutation in the tyrosine kinase domain of VEGFR3 (Karkkainen et al., 2000). Elucidation of the precise function and interaction of the different molecular players will thus certainly lead to the development of novel treatments for vascular disorders. A particularly interesting aspect of recent research carried out on the vascular system is the identification of neural guidance receptors such as ephrins and neuropilins, which are expressed on arteries, veins and lymphatic vessels. In the nervous system, these molecules are implicated in the establishment of cell boundaries and in the guidance of developing axons. It is thus tempting to speculate that these receptors may also play a role in vessel guidance during embryonic development. Indeed, recent studies have shown that specialized cells termed 'tip cells' are present at the ends of developing vessel sprouts, which extend filipodia that explore their environment in much the same way as the growth cone of a developing axon (Gerhardt et al., 2003; Ruhrberg et al., 2002). Moreover, the patterning of developing arteries in the limb skin of mouse embryos has been shown to depend on interactions with nerves (Mukouyama et al., 2002), emphasizing the close interaction between the two systems. Future studies will be directed at exploring the precise interactions between blood vessels and nerves during development as well as in pathologies.

\section{References}

ADAMS, R. H., WILKINSON, G. A., WEISS, C., DIELLA, F., GALE, N. W., DEUTSCH, U., RISAU, W. and KLEIN, R. (1999). Roles of ephrinB ligands and EphB receptors in cardiovascular development: demarcation of arterial/venous domains, vascular morphogenesis and sprouting angiogenesis. Genes Dev 13: 295-306.

ALITALO, K. and CARMELIET, P. (2002). Molecular mechanisms of lymphangiogenesis in health and disease. Cancer Cell 1: 219-227.

ARTAVANIS-TSAKONAS, S., RAND, M. D. and LAKE, R. J. (1999). Notch signaling: cell fate control and signal integration in development. Science 284: 770-776.

CARMELIET, P., FERREIRA, V., BREIER, G., POLLEFEYT, S., KIECKENS, L., GERTSENSTEIN, M., FAHRIG, M., VANDENHOECK, A., HARPAL, K., EBERHARDT, C., DECLERCQ, C., PAWLING, J., MOONS, L., COLLEN, D., RISAU, W. and NAGY, A. (1996). Abnormal blood vessel development and lethality in embryos lacking a single VEGF allele. Nature 380: 435-439.

CARMELIET, P. and JAIN, R. K. (2000). Angiogenesis in cancer and other diseases. Nature 407: 249-257.

CHOI, K., KENNEDY, M., KAZAROV, A., PAPADIMITRIOU, J. C. and KELLER, G. (1998). A common precursor for hematopoietic and endothelial cells. Development 125: 725-732.

CINES, D. B., POLLAK, E. S., BUCK, C. A., LOSCALZO, J., ZIMMERMAN, G. A., MCEVER, R. P., POBER, J. S., WICK, T. M., KONKLE, B. A., SCHWARTZ, B. S., BARNATHAN, E. S., MCCRAE, K. R., HUG, B. A., SCHMIDT, A. M. and STERN, D. M. (1998). Endothelial cells in physiology and in the pathophysiology of vascular disorders. Blood 91: 3527-3561.

CUMANO, A., FERRAZ, J. C., KLAINE, M., DI SANTO, J. P. and GODIN, I. (2001). Intraembryonic, but not yolk sac hematopoietic precursors, isolated before circulation, provide long-term multilineage reconstitution. Immunity 15: 477485.

DIETERLEN-LIEVRE, F. (1975). On the origin of haemopoietic stem cells in the avian embryo: an experimental approach. J Embryo/ Exp Morpho/ 33: 607-619.

DUMONT, D. J., JUSSILA, L., TAIPALE, J., LYMBOUSSAKI, A., MUSTONEN, T., PAJUSOLA, K., BREITMAN, M. and ALITALO, K. (1998). Cardiovascular failure in mouse embryos deficient in VEGF receptor-3. Science 282: 946-949.

EICHMANN, A., CORBEL, C., NATAF, V., VAIGOT, P., BREANT, C. and LE DOUARIN, N. M. (1997). Ligand-dependent development of the endothelial and hemopoietic lineages from embryonic mesodermal cells expressing vascular endothelial growth factor receptor 2. Proc Nat/ Acad Sci USA 94: 5141-5146.

EICHMANN, A., MARCELLE, C., BREANT, C. and LE DOUARIN, N. M. (1993). Two molecules related to the VEGF receptor are expressed in early endothelial cells during avian embryonic development. Mech Dev 42: 33-48. 
FERRARA, N. and ALITALO, K. (1999). Clinical applications of angiogenic growth factors and their inhibitors. Nat Med 5: 1359-1364.

FERRARA, N., CARVER-MOORE, K., CHEN, H., DOWD, M., LU, L., O'SHEA, K. S., POWELL-BRAXTON, L., HILLAN, K. J. and MOORE, M. W. (1996). Heterozygous embryonic lethality induced by targeted inactivation of the VEGF gene. Nature 380: 439-442.

FLANAGAN, J. G. and VANDERHAEGHEN, P. (1998). The ephrins and Eph receptors in neural development. Annu Rev Neurosci 21: 309-345.

FOLKMAN, J. (1995). Angiogenesis in cancer, vascular, rheumatoid and other disease. Nat Med 1: 27-31.

GERETY, S. S., WANG, H. U., CHEN, Z. F. and ANDERSON, D. J. (1999). Symmetrical mutant phenotypes of the receptor EphB4 and its specific transmembrane ligand ephrin-B2 in cardiovascular development. $\mathrm{Mo} / \mathrm{Ce} / / \mathrm{H}$ : 403-414.

GERHARDT, H., GOLDING, M., FRUTTIGER, M., RUHRBERG, C., LUNDKVIST, A., ABRAMSSON, A., JELTSCH, M., MITCHELL, C., ALITALO, K., SHIMA, D. and BETSHOLTZ, C. (2003). VEGF guides angiogenic sprouting utilizing endothelial tip cell filopodia. J Cel/ Biol 161: 1163-1177.

HAMBURGER, V. and HAMILTON, H. L. (1951). A series of normal stages in the development of chick embryo. J Morphol 88: 49-92.

HERZOG, Y., KALCHEIM, C., KAHANE, N., RESHEF, R. and NEUFELD, G. (2001). Differential expression of neuropilin-1 and neuropilin-2 in arteries and veins. Mech Dev 109: 115-119.

HUNTINGTON, S. G. and MCCLURE, C. F. W. (1908). The anatomy and development of the jugular lymph sac in the domestic cat (Felis domestica). Anat. Rec. 2: 1-19.

JAFFREDO, T., GAUTIER, R., EICHMANN, A. and DIETERLEN-LIEVRE, F. (1998). Intraaortic hemopoietic cells are derived from endothelial cells during ontogeny. Development 125: 4575-4583.

JAKEMAN, L. B., ARMANINI, M., PHILLIPS, H. S. and FERRARA, N. (1993). Developmental expression of binding sites and messenger ribonucleic acid for vascular endothelial growth factor suggests a role for this protein in vasculogenesis and angiogenesis. Endocrinology 133: 848-859.

KAIPAINEN, A., KORHONEN, J., MUSTONEN, T., VAN HINSBERGH, V. W. FANG, G. H., DUMONT, D., BREITMAN, M. and ALITALO, K. (1995). Expression of the fms-like tyrosine kinase 4 gene becomes restricted to lymphatic endothelium during development. Proc Nat/ Acad Sci USA 92: 3566-3570.

KAMPMEIER, O. F. (1912). The value of the injection method in the study of lymphatic development. Anat Rec 6.

KARKKAINEN, M.J., HAIKO, P., SAINIO, K., PARTANEN, J., TAIPALE, J., PETROVA, T.V., JELTSCH, M., JACKSON, D.G., TALIKKA, M., RAUVALA, H., BETSHOLTZ, C. and ALITALO, K. (2004). Vascular endothelial growth factor C is required for sprouting of the first lymphatic vessels from embryonic veins. Nat Immunol. 5: 74-80.

KARKKAINEN, M. J., FERRELL, R. E., LAWRENCE, E. C., KIMAK, M. A., LEVINSON, K. L., MCTIGUE, M. A., ALITALO, K. and FINEGOLD, D. N. (2000). Missense mutations interfere with VEGFR-3 signalling in primary lymphoedema. Nat Genet 25: 153-159.

KARKKAINEN, M. J., MAKINEN, T. and ALITALO, K. (2002) Lymphatic endothelium: a new frontier of metastasis research. Nat Cell Biol 4: E2-5.

KARKKAINEN, M. J., SAARISTO, A., JUSSILA, L., KARILA, K. A., LAWRENCE, E. C., PAJUSOLA, K., BUELER, H., EICHMANN, A., KAUPPINEN, R., KETTUNEN, M. I., YLA-HERTTUALA, S., FINEGOLD, D. N., FERRELL, R. E. and ALITALO, K. (2001). A model for gene therapy of human hereditary lymphedema.n Proc Natl Acad Sci USA 98: 12677-12682.

KAWASAKI, T., KITSUKAWA, T., BEKKU, Y., MATSUDA, Y., SANBO, M., YAGI, T. and FUJISAWA, H. (1999). A requirement for neuropilin-1 in embryonic vessel formation. Development 126: 4895-4902.

KULLANDER, K. and KLEIN, R. (2002). Mechanisms and functions of Eph and ephrin signalling. Nat Rev Mol Cell Biol 3: 475-486.

LAWSON, N. D., SCHEER, N., PHAM, V. N., KIM, C. H., CHITNIS, A. B., CAMPOSORTEGA, J. A. and WEINSTEIN, B. M. (2001). Notch signaling is required for arterial-venous differentiation during embryonic vascular development. Development 128: 3675-3683

LE NOBLE, F., MOYON, D., PARDANAUD, L., YUAN, L., DJONOV, V., MATTHIJSEN, R., BREANT, C., FLEURY, V. and EICHMANN, A. (2004). Flow regulates arterial-venous differentiation in the chick embryo yolk sac. Development 131: 361-75.

MOYON, D., PARDANAUD, L., YUAN, L., BREANT, C. and EICHMANN, A (2001a). Plasticity of endothelial cells during arterial-venous differentiation in the avian embryo. Development 128: 3359-3370.

MOYON, D., PARDANAUD, L., YUAN, L., BREANT, C. and EICHMANN, A (2001b). Selective expression of angiopoietin 1 and 2 in mesenchymal cells surrounding veins and arteries of the avian embryo. Mech Dev 106: 133-136.

MUKOUYAMA, Y. S., SHIN, D., BRITSCH, S., TANIGUCHI, M. and ANDERSON, D. J. (2002). Sensory nerves determine the pattern of arterial differentiation and blood vessel branching in the skin. Cell 109: 693-705.

MURRAY, P. (1932). The development «in vitro» of blood of the early chick embryo. Proc Roy. Soc. 111: 497-521.

NEUFELD, G., COHEN, T., SHRAGA, N., LANGE, T., KESSLER, O. and HERZOG, $Y$. (2002). The neuropilins: multifunctional semaphorin and VEGF receptors that modulate axon guidance and angiogenesis. Trends Cardiovasc Med 12 13-19.

NISHIKAWA, S. I., NISHIKAWA, S., HIRASHIMA, M., MATSUYOSHI, N. and KODAMA, H. (1998). Progressive lineage analysis by cell sorting and culture identifies FLK1+VE-cadherin + cells at a diverging point of endothelial and hemopoietic lineages. Development 125: 1747-1757.

PARDANAUD, L., ALTMANN, C., KITOS, P., DIETERLEN-LIEVRE, F. and BUCK C. A. (1987). Vasculogenesis in the early quail blastodisc as studied with a monoclonal antibody recognizing endothelial cells. Development 100: 339-349.

PARDANAUD, L., LUTON, D., PRIGENT, M., BOURCHEIX, L. M., CATALA, M. and DIETERLEN-LIEVRE, F. (1996). Two distinct endothelial lineages in ontogeny, one of them related to hemopoiesis. Development 122: 1363-1371.

RAPER, J. A. (2000). Semaphorins and their receptors in vertebrates and invertebrates. Curr Opin Neurobiol 10: 88-94.

RISAU, W. (1997). Mechanisms of angiogenesis. Nature 386: 671-674.

ROMAN, B. L. and WEINSTEIN, B. M. (2000). Building the vertebrate vasculature research is going swimmingly. Bioessays 22: 882-893.

RUHRBERG, C., GERHARDT, H., GOLDING, M., WATSON, R., IOANNIDOU, S., FUJISAWA, H., BETSHOLTZ, C. and SHIMA, D. T. (2002). Spatially restricted patterning cues provided by heparin-binding VEGF-A control blood vesse branching morphogenesis. Genes Dev 16: 2684-2698.

SABIN, F. (1902). On the origin of the lymphatic system from the veins and the decelopment of the lymph hearts and thoracic duct in the pig. Am JAnat 1:367391.

SABIN, F. R. (1920). Studies on the origin of blood-vessels and of red blood corpuscules as seen in the living blastoderm of chicks during the second day of incubation. Carnegie Contrib. Embryol. 272: 214-262.

SCHNEIDER, M., OTHMAN-HASSAN, K., CHRIST, B. and WILTING, J. (1999). Lymphangioblasts in the avian wing bud. Dev Dyn 216: 311-319.

SHALABY, F., ROSSANT, J., YAMAGUCHI, T. P., GERTSENSTEIN, M., WU, X. F., BREITMAN, M. L. and SCHUH, A. C. (1995). Failure of blood-island formation and vasculogenesis in Flk-1-deficient mice. Nature 376: 62-66.

SHUTTER, J. R., SCULLY, S., FAN, W., RICHARDS, W. G., KITAJEWSKI, J., DEBLANDRE, G. A., KINTNER, C. R. and STARK, K. L. (2000). DIl4, a novel Notch ligand expressed in arterial endothelium. Genes Dev 14: 1313-1318.

SHWEIKI, D., ITIN, A., NEUFELD, G., GITAY-GOREN, H. and KESHET, E. (1993). Patterns of expression of vascular endothelial growth factor (VEGF) and VEGF receptors in mice suggest a role in hormonally regulated angiogenesis. $J$ Clin Invest 91: 2235-2243.

STEPHAN, F. (1952). Contribution expérimentale l'Étude du développement du système circulatoire chez l'embryon de poulet. In «Bulletin Biologique de la France et de la Belgique» (L. P. U. d. France, Ed.), Vol. LXXXVI, pp. 218-310, Paris.

SWIATEK, P. J., LINDSELL, C. E., DEL AMO, F. F., WEINMASTER, G. and GRIDLEY, T. (1994). Notch1 is essential for postimplantation development in mice. Genes Dev 8: 707-719.

THOMA, R. (1893). «Untersuchungen über die Histogenese und Histomechanik des Gefssytems.» Ferdinand Enke, Stuttgart.

VAKAET, L. (1985). «Morphogenetic movements and fate maps in the avian blastoderm.» G.M. Edelman, New York. 
VILLA, N., WALKER, L., LINDSELL, C. E., GASSON, J., IRUELA-ARISPE, M. L. and WEINMASTER, G. (2001). Vascular expression of Notch pathway receptors and ligands is restricted to arterial vessels. Mech Dev 108: 161-164.

WANG, H. U., CHEN, Z. F. and ANDERSON, D. J. (1998). Molecular distinction and angiogenic interaction between embryonic arteries and veins revealed by ephrin-B2 and its receptor Eph-B4. Cell 93: 741-753.

WHEATER, P. R., BURKITT, H. G. and DANIELS, V. G. (1978). «Functional Histology: a Text and Colour Atlas.» Churchill Livestone,

WIGLE, J. T., HARVEY, N., DETMAR, M., LAGUTINA, I., GROSVELD, G., GUNN, M. D., JACKSON, D. G. and OLIVER, G. (2002). An essential role for Prox1 in the induction of the lymphatic endothelial cell phenotype. EMBO J 21: 15051513.

WIGLE, J. T. and OLIVER, G. (1999). Prox1 function is required for the development of the murine lymphatic system. Cell 98: 769-778.

WILTING, J., EICHMANN, A. and CHRIST, B. (1997). Expression of the avian VEGF receptor homologues Quek1 and Quek2 in blood-vascular and lymphatic endothelial and non-endothelial cells during quail embryonic development. Cel/ Tissue Res 288: 207-223.

WILTING, J., PAPOUTSI, M., OTHMAN-HASSAN, K., RODRIGUEZ-NIEDENFUHR, M., PROLS, F., TOMAREV, S. I. and EICHMANN, A. (2001). Development of the avian lymphatic system. Microsc Res Tech 55: 81-91.

WILTING, J., PAPOUTSI, M., SCHNEIDER, M. and CHRIST, B. (2000). The lymphatic endothelium of the avian wing is of somitic origin. Dev Dyn 217: 271-278.

XUE, Y., GAO, X., LINDSELL, C. E., NORTON, C. R., CHANG, B., HICKS, C., GENDRON-MAGUIRE, M., RAND, E. B., WEINMASTER, G. and GRIDLEY, T. (1999). Embryonic lethality and vascular defects in mice lacking the Notch ligand Jagged1. Hum Mol Genet 8: 723-730.

YAMAGUCHI, T. P., DUMONT, D. J., CONLON, R. A., BREITMAN, M. L. and ROSSANT, J. (1993). flk-1, an flt-related receptor tyrosine kinase is an early marker for endothelial cell precursors. Development 118: 489-498.

YAMASHITA, J., ITOH, H., HIRASHIMA, M., OGAWA, M., NISHIKAWA, S., YURUGI, T., NAITO, M. and NAKAO, K. (2000). Flk1-positive cells derived from embryonic stem cells serve as vascular progenitors. Nature 408: 92-96.

YANCOPOULOS, G. D., DAVIS, S., GALE, N. W., RUDGE, J. S., WIEGAND, S. J. and HOLASH, J. (2000). Vascular-specific growth factors and blood vessel formation. Nature 407: 242-248.

YUAN, L., MOYON, D., PARDANAUD, L., BREANT, C., KARKKAINEN, M. J., ALITALO, K. and EICHMANN, A. (2002). Abnormal lymphatic vessel development in neuropilin 2 mutant mice. Development 129: 4797-4806.

ZHONG, T. P., CHILDS, S., LEU, J. P. and FISHMAN, M. C. (2001). Gridlock signalling pathway fashions the first embryonic artery. Nature 414: 216-220.

ZHONG, T. P., ROSENBERG, M., MOHIDEEN, M. A., WEINSTEIN, B. and FISHMAN, M. C. (2000). gridlock, an HLH gene required for assembly of the aorta in zebrafish. Science 287: 1820-1824. 